\title{
Relações Fitogeomorfológicas da Bacia Hidrográfica do Rio Curu, Ceará- Brasil: Uma abordagem preliminar
}

\author{
Phytogeomorphology relations Basin Hydrographic the Curu, Cerá- Brazil River. A \\ preliminary approach.
}

Mendes 1 , L. S.; Bastos², F. H.

mendes.luciana@hotmail.com

\begin{abstract}
Resumo
O semiárido nordestino apresenta considerável grau de heterogeneidade fisiográfica, condicionado por uma dinâmica natural complexa. Nessa perspectiva se destaca a Bacia Hidrográfica do Rio Curu, com grande diversidade paisagística no contexto cearense, tendo em vista as inúmeras relações existentes entre os componentes ambientais. Sua área de drenagem de 8.534 $\mathrm{km}^{2}$ corresponde a cerca de $6 \%$ do território estadual. Face ao exposto, o presente trabalho visa, através de um método de análise fitogeomorfológica, relacionar o relevo com a distribuição vegetal da área, subsidiando o monitoramento, gestão e conservação do ambiente. $\mathrm{O}$ trabalho tem como metodologia levantamento de campo, revisão bibliográfica, interpretação de imagens de sensoriamento remoto, compilação das informações obtidas e elaboração da pesquisa. Após as discussões e diagnósticos da área, foi apresentado a cada unidade geomorfológica o desenvolvimento de uma cobertura vegetal adaptada a morfodinâmica da área em que se insere. Nos maciços residuais ocorre a presença de mata pluvionebular e mata seca, as caatingas desenvolvem-se na depressão sertaneja, a mata ciliar percorre as planícies fluviais, nos tabuleiros pré-litorâneos ocorre a mata de tabuleiro, e por fim, na planície costeira, há um complexo vegetacional litorâneo, com destaque para o manguezal.
\end{abstract}

Palavras-chave: Semiárido Brasileiro, Geomorfologia e Fitogeografia .

\begin{abstract}
The Brazilian semiarid region presents considerable heterogeneity physiographic, conditioned by a complex natural dynamics. From this perspective highlights the Basin Curú River with great diversity in Ceará context, considering the numerous relationships between environmental components. Its total area is 8,534 square kilometers and is about $6 \%$ of the state. Thus, this paper aims, by a method of phytogeomorphological analysis, relate relief with vegetation distribution, supporting the monitoring, management and conservation of the environment. This work was drawn from field survey, literature review, remote sensing imagery interpretation, compilation of information obtained and development of research. After discussions and diagnosis of the basin area, was presented to each geomorphological unit phytogeographical representative adapted to the morphodynamics of the area. In the massive notes the presence of pluvionebular forest and dry forest, the caatingas develop in the erosion surfaces, the gallery forest occur in the fluvial plains, in the pre-coastal plains notes to semideciduous forest and, finally, on the coastal plain there is the coastal vegetation, especially mangroves.
\end{abstract}

Keywords: Brazilian semiarid, Geomorphology and Phytogeography.

\section{INTRODUÇÃO}

Localizado no Nordeste brasileiro, o Estado do Ceará está inserido dentro do domínio das caatingas semiáridas com uma dinâmica ambiental própria e bastante discutida frente às demais paisagens do país. De acordo com Ab’Saber (1970), as diferentes paisagens sintetizadas em

\footnotetext{
${ }^{1}$ Luciana Sousa Mendes, Centro de ciências e Tecnologial Laboratório de Estudos Morfoestruturais e Pedológicos- LEMEP, Universidade Estadual do Ceará- UECE, Fortaleza-CE, Brasil

${ }^{2}$ Frederico de Holanda Bastos, Centro de Ciências e Tecnologia / Laboratório de Estudos Morfoestruturais e Pedológicos- LEMEP, Universidade Estadua do Ceará- UECE,Fortaleza-CE, Brasil
} 
mosaicos de grandes domínios morfoclimáticos e suas "variantes endógenas", somente poderão ser melhor compreendidas com aprofundamento de estudos fisiográficos e biogeográficos integrados.

O cenário físico cearense é destacado pela presença de extensas superfícies aplainadas (depressão sertaneja) com elevações modestas resultantes da forte atuação de processos erosivos e denudacionais, ao longo das variações climáticas do Quaternário. A presença de rochas mais resistentes condiciona a erosão diferencial, desenvolvendo feições geomorfológicas residuais nas depressões sertanejas, os inselbergs. A pedogênese cenozóica nos sertões, predominantemente associada a clima seco, favoreceu o desenvolvimento de solos rasos, pedregosos e com relativa fertilidade natural.

A atual configuração geomorfológica do Ceará tem relação direta com o processo de abertura do oceano Atlântico Equatorial durante o Cretáceo. Levando em consideração a formação das paisagens nordestinas, Maia, Bezerra e Claudino Sales (2010) consideram que durante a divisão do megacontinente Pangea, essas paisagens desenvolveram-se sobre zonas de cizalhamento que foram reativadas durante o Cretáceo e o Cenozóico, originando áreas arqueadas que, uma vez submetidas à erosão diferencial, formam alinhamento de cristas com direções preferenciais NE-SW e E-W.

Em meio ao semiárido brasileiro, a bacia hidrográfica do rio Curu é marcada por consideráveis limitações em sua capacidade produtiva e de suporte, por interferência de fatores naturais e humanos, porém, se destaca como uma das mais importantes do Estado, sendo responsável pela drenagem de 15 municípios.

Localiza-se no Centro-Norte do Estado do Ceará (Figura1), limitando-se, a leste, com as bacias Metropolitanas, a oeste com as bacias do Acaraú e do Litoral e ao sul com a sub-bacia do rio Banabuiú, integrante do Sistema do Jaguaribe. Seu principal afluente é o rio Canindé, que se encontra na margem direita, e drena praticamente todo o quadrante sudeste da bacia. Pela margem esquerda destaca-se o rio Caxitoré (SRH, 1992). O rio Curu possui uma extensão de $195 \mathrm{~km}$ corre preferencialmente no sentido SW-NE. Drena uma área de $8.750,75 \mathrm{Km}^{2}$, o equivalente a $6 \%$ do território cearense (INESP, 2009). 


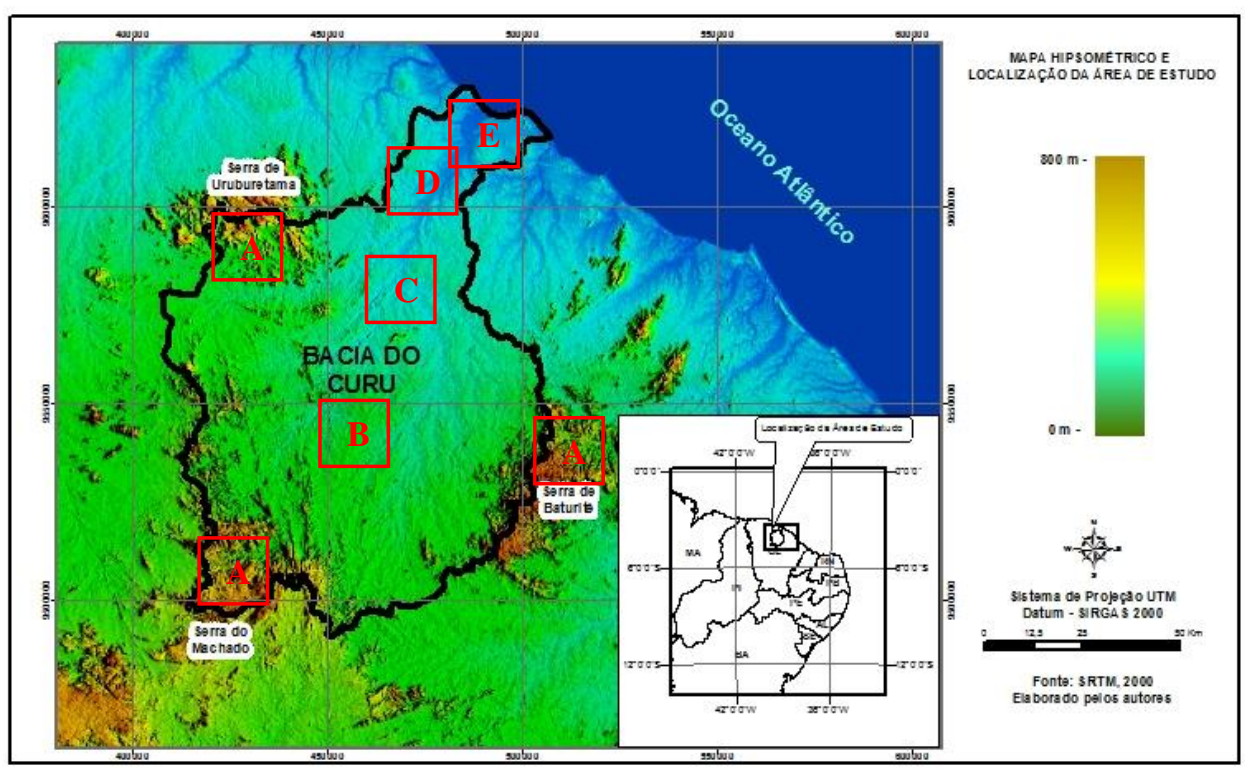

Figura 1: Localização da Bacia Hidrográfica do Curu. Fonte: Elaborado pelos autores

O rio Curu apresenta importantes reservatórios como os açudes de General Sampaio, Pentecoste e Caxitoré, desembocando no oceano Atlântico através de um estuário sinuoso no limite entre os municípios de Paraipaba e Paracuru. (SOUZA; SANTOS; OLIVEIRA, 2012).

De modo geral as bacias hidrográficas apresentam essencial relevância no que concerne a estudos de planejamento e conservação ambiental, tendo em vista a possibilidade de se analisar a gestão dos recursos hídricos e do meio ambiente numa mesma unidade territorial.

As atividades econômicas realizadas na área da Bacia do Rio Curu, juntamente com a proximidade com a capital do Estado, fazem dela um grande recurso de investimento e exploração. Portanto, a análise ambiental da área de forma integrada se torna importante, tendo em vista uma melhor utilização dos recursos naturais disponíveis. Nesse sentido, procura-se através de uma abordagem fitogeomorfológica um método alternativo de análise ambiental.

Em sua área de abrangência, a referida bacia hidrográfica comporta diferentes ambientes e paisagens, consequência das diferenciações litológicas, variação pluviométrica, complexidade morfológica e cobertura florestal. Compõe uma unidade de análise que possibilita mensurar a relação de fatores geomorfológicos e fitogeográficos consideráveis. Guerra e Cunha (2003) consideram o meio físico como um ambiente dinâmico, onde durante toda a história da Terra sofreu importantes mudanças climáticas e geomorfológicas resultando no surgimento de ambientes com características bem variadas.

O estudo paisagístico da área procura sustentar-se em uma análise fitogeomorfológica aliada aos aspectos dinâmicos de evolução da natureza junto às possíveis intervenções antrópicas. Segundo Passos (2010), o estudo fitogeomorfológico apresenta um vasto campo de aplicação a ser 
explorado e aperfeiçoado, pois, além de facilitar a compreensão da origem, evolução, divisão e correlação de componentes da paisagem, facilita ainda a avaliação com maior abrangência de impactos produzidos por fenômenos naturais ou ações antrópicas no meio ambiente, assim como, determinar seu potencial de utilização.

Passos (2010) afirma que o estudo da organização espacial de seus elementos e de suas unidades integradas, na classificação da paisagem, tem utilizado a compartimentação geomorfológica como um dos principais critérios de mapeamento. Para Souza (1973) esses estudos representam elementos imprescindíveis para um conhecimento adequado do ambiente e, como tal, base para levantamentos ecológicos, fitogeográficos, pedológicos etc.

A partir do reconhecimento das unidades geomorfológicas em que a Bacia do Curu se insere, pretende-se analisar de que forma o relevo pode influenciar nas manifestações vegetacionais da área levando em consideração a dinâmica natural local indicando assim a capacidade de suporte e estabilidade ecológica de cada unidade, subsidiando o monitoramento, gestão e conservação do ambiente.

\section{METODOLOGIA}

A ciência geomorfológica vem se fortalecendo a partir da segunda metade do século $\mathrm{XX}$, com novas formas de abordagens oriundas de contribuições científicas de outros ramos das ciências naturais. Dentro dessa lógica, a fitogeomorfologia surge como uma ciência alternativa, de caráter interdisciplinar, pois, favorece o aprofundamento do reconhecimento de padrões fitoecológicos aliados às formações geomorfológicas atuantes, além de ser um ótimo recurso de análise para interpretação ambiental, procurando novas abordagens integradas da paisagem, contribuindo para o aprofundamento no campo geomorfológico e fitogeográfico.

Com base sistêmica, objetiva-se a compartimentação em unidades de paisagem por meio de critérios de classificação fitogeomorfológico. Fernandes (2007) destaca a necessidade de incluir a compartimentação geomorfológica, bem como aspectos pedológicos e hidrológicos nos estudos fitogeográficos para marcar o complexo ecológico daí resultante.

Para Passos (2000), o estudo fítogeomorfológico possibilita correlacionar a distribuição de espécies e a morfologia do relevo com tipos de solos e consequentemente inferir o limite de sítios florestais entre outros fatores ambientais, como entender a própria distribuição da vegetação e de suas relações com a estabilidade ambiental.

Para uma melhor organização metodológica, o trabalho foi dividido em quatro etapas. Inicialmente foram levantados materiais bibliográficos/cartográficos e seleções de publicações 
acadêmicas com informações pertinentes a área em estudo e aos componentes da paisagem, dando ênfase qualitativa a geomorfologia e a fitogeografia.

$\mathrm{Na}$ segunda etapa da pesquisa, foram feitos levantamentos cartográficos tendo como principal base o mapa geológico da CPRM (2003) na escala de 1:500.000, e técnicas de geoprocessamento, na qual resultou em um mapa hipsométrico e de localização da área de estudo.

$\mathrm{Na}$ terceira etapa foram feitos levantamentos de campo em pontos específicos da área para coleta de dados e interpretação da realidade terrestre, com auxílio de GPS e máquina fotográfica. Por último, a compilação de informações obtidas na pesquisa e elaboração do relatório final.

\section{RESULTADOS E DISCUSSÃO}

O termo "fitogeomorfologia" encontrado em trabalhos de Howard e Mitchell (1980); Howard (1991) e Passos (1997; 2000), procuram fazer uma relação entre as características geomorfológicas e as manifestações vegetais, considerando-as como resultado de um longo processo evolutivo. Uma vez que esses componentes ambientais facilmente perceptíveis aparecem juntos, é um importante recurso de síntese e de fácil mapeamento para fins de ordenamento do território. Passos (2000) considera o relevo e a vegetação como os principais fatores ambientais observáveis, cujo estudo combinado conforme, Howard (1991), denomina-se "Phytogeomorfology". Porém, não podem ser considerados irrelevantes os demais componentes ambientais.

Orientando-se pela classificação de Souza (1988), a distribuição espacial da Bacia do Rio Curu se dá, de modo geral, em cinco unidades geomorfológicas, são elas: Os maciços residuais cristalinos abrangendo suas nascentes e compondo os médios e altos vales do Curu, onde na margem esquerda localiza-se a serra do Machado, também alimentados por tributários da serra de Uruburetama e na margem direita o maciço de Baturité, sendo recobertos por mata úmida e mata seca; a depressão sertaneja, na qual se trata de vastas superfícies de erosão recobertas por caatingas; as planícies fluviais com boas condições de solos e presença de mata ciliar; os tabuleiros prélitorâneos, que constituem superfícies tabulares de deposição de sedimentos da Formação Barreiras, e recobertos pelas matas de tabuleiro; e as planícies litorâneas que tratam-se das unidades geomorfológicas mais recentes, situadas na zona costeira, sob influência de processos de origem continental e oceânica e recobertas por uma unidade fitoecológica denominada de complexo vegetacional litorâneo, com ocorrência de manguezais.

A primeira unidade geomorfológica aqui exposta são os maciços residuais (destacados na Figura 1 pela letra A) que, de acordo com as concepções clássicas, são formadas pelo recuo paralelo 
das vertentes, na qual possuem papel relevante na formação da bacia hidrográfica do Rio Curú, compondo suas nascentes, sendo eles: Baturité, Machado e Uruburetama. Essas unidades de paisagem são consideradas ambientes atípicos dentro do contexto semiárido nordestino, em algumas literaturas, tais como Ab'Sáber (2003); Souza e Oliveira (2006); Fernandes,(2007), ganham o nome de "enclaves úmidos" no domínio das caatingas, com exceção da serra do Machado, que trata-se de uma serra seca. Possuem superfícies topograficamente elevadas que condicionam mesoclima de altitude, na qual desenvolvem boas condições edafoclimáticas e hídricas.

Os tipos vegetacionais que se desenvolveram nesses ambientes variam de acordo com sua localização e circulação atmosférica. Nas serras de Ururetama e Baturité ocorre a presença de mata pluvio-nebular que colonizaram esses ambientes ao longo de transições climáticas do Quaternário. Esse fato pode ser explicado através da Teoria dos Refúgios e Redutos, onde segundo Ab’Sáber (1988), trata-se das repercussões das mudanças climáticas quaternárias sobre o quadro distributivo de floras e faunas, em tempos determinados, ao longo de espaços fisiográficos, paisagistas e ecologicamente mutantes. Também abriga nas áreas de sotavento desses maciços, a mata seca, em sua transição com as caatingas, porém, a serra do Machado na porção central é considerada uma serra totalmente seca, revestida por vegetação de caatinga.

Compondo a maior parte da bacia, o segundo componente geomorfológico é a depressão sertaneja (destacado na Figura 1 pela letra B). Para Claudino Sales e Lira (2011), as superfícies aplainadas sertanejas foram formadas pela erosão diferencial, comandada por processos lineares e areolares. Tal unidade apresenta-se suavemente dissecada, com ondulações que se estendem ao litoral. Ainda nessa unidade aparecem relevos residuais em grupos ou isolados, mais conhecidos por inselbergs.

A depressão sertaneja é recoberta pelo domínio das caatingas, uma vegetação exclusivamente brasileira, comprometida em parte pelo mau uso e pela deficiência administrativa por parte do poder público no que tange à sua proteção.

A estabilização do clima semiárido nordestino desencadeou uma paisagem sertaneja exclusiva, dentro de um contexto tropical de baixas latitudes. Esse ambiente é resultado de processos complexos de massas de ar e circulação atmosférica que contribuem para certa irregularidade pluviométrica anual e altas temperaturas, aumentando o grau de evapotranspiração que limitam a disponibilidade hídrica superficial e subterrânea.

Adaptando-se a essa complexa dinâmica ambiental, as caatingas apresentam-se heterogêneas ao longo de seu domínio paisagístico. Como forma de evitar ausência hídrica, as plantas perdem as folhas nos períodos de estiagem e outras possuem estruturas adaptadas ao armazenamento de água, 
é o caso das cactáceas. Figueiredo (1997) dividiu as caatingas do cristalino entre arbórea, arbustiva densa e arbustiva aberta.

As planícies fluviais (destacadas na Figura 1 pela letra C) compõem o domínio dos depósitos sedimentares cenozóicos e variam de acordo com a capacidade de transporte e da deposição de sedimento pelas correntes fluviais, sendo, portanto, ambientes de deposição sem grande amplitude altimétrica entre fundos de vales e interflúvios tabulares. Gorayeb et al. (2005) afirma que nas planícies fluviais do Curu e de seus principais afluentes, pode-se observar pequenos trechos de Mata Ciliar preservadas, onde se encontram, eventualmente, a carnaúba (Copernicia prunifera).

Outra unidade geomorfológica da bacia do Curu, são os tabuleiros pré-litorâneos (destacado na Figura 1 pela letra D) que, para Bezerra e Maia (2012), representam a faixa de transição entre o domínio das terras altas e da planície costeira, moldados nos sedimentos cenozóicos da Formação Barreiras. Para Bigarella e Andrade (1964), "Formação Barreiras" ou "Série Barreiras" são designados aos sedimentos afossilíferos de origem continental, pouco consolidados.

Essa unidade apresenta forma tabular, levemente dissecada que se estende do interior ao litoral de forma suavemente inclinada, comportando-se como um glacis de acumulação. Soares (2004) afirma que o tabuleiro pré-litorâneo formou a jusante do Curu, preenchendo microbacias dispostas em semicírculo. Foi desenvolvida uma cobertura florestal de caatinga hiperxerófila de porte arbustivo-herbáceo. Compõe uma vegetação atual denominada Vegetação Subcaducifólia de Tabuleiro, ou seja, podem perder sua folhagem nos períodos de estiagem, tendo como principais bioindicadores os cajueiros.

Ainda compondo os depósitos de acumulação cenozóica, mais precisamente do Holoceno, apresenta-se a planície litorânea (destacado na Figura 1 pela letra E), se distribui entre campos de dunas e extensas faixas de areias quartzosas, bem como planícies flúvio-marinhas estas compostas por argilas e matéria orgânica. Nas faixas de praia há a presença de gramíneas, ciperáceas e espécies herbáceas, nos campos de dunas ocorrem dunas fixas. Gorayeb (2005) considera ainda a presença de Vegetação Subperenifólia de Dunas, onde varia segundo a altura da duna, posição do vento, incidência solar, a barlavento se torna arbustivo e a sotavento arbóreo.

Segundo Landim Neto et al. (2013), a planície flúvio-marinha do rio Curu possui relevo plano e tem sua dinâmica condicionada ao regime pluviométrico e às oscilações das marés. Pouco expressiva, geograficamente, é composta pela Vegetação Paludosa de Mangue que apresenta: mangue vermelho (Rhizophora mangle), mangue preto (Avicennia schaueriana e Avicennia germinans), mangue branco (Laguncularia racemosa) e mangue botão (Conocarpus erectus). 
Localizada entre os municípios de Paracuru e Paraipaba, os estuários são locais vulneráveis a intervenções antrópicas, em contrapartida, as áreas de mangue possuem extrema importância para a biodiversidade marinha.

É importante destacar os altos níveis de extrativismo vegetal para atividades humanas em todas as unidades da bacia. Ao longo das pesquisas foi possível apreender a realidade de níveis de degradação, com destaque no alto e médio curso, já no baixo curso variam entre parcialmente degradada e degradada, na qual compromete a qualidade de armazenamento e qualidade hídrica, por conta da sedimentação provocada pelo assoreamento do rio Curu.

\section{CONSIDERAÇÕES FINAIS}

As mudanças na terra, sejam elas climáticas ou geomorfológicas, possibilitaram o surgimento de ambientes diferentes e com dinâmicas próprias, onde as respostas dessas mudanças são facilmente observáveis na vegetação. As diferenciações na cobertura vegetal podem ocorrer pela sua adaptação ao clima, posição geográfica, altitude, orientação de vertentes, solos, incidência solar etc.

Considerando o relevo como condicionante fundamental na paisagem, observou-se que em meio a um domínio morfoclimático maior, a cobertura vegetal se diferencia ao longo das cinco unidades geomorfológicas, como resultado dos componentes ambientais específicos.

Levando em consideração a vegetação como um recurso de exploração humana, em contrapartida, elemento fundamental para proteção dos solos e equilíbrio da biodiversidade, é relevante qualquer estudo que vise o conhecimento da dinâmica natural das paisagens e influência da intervenção humana.

Portanto, esse nível de interpretação poderá ser utilizado em outros estudos de bacias, auxiliando no monitoramento e gestão dos recursos naturais disponíveis.

\section{REFERÊNCIAS}

AB'SÁBER, A. N. Províncias geológicas e domínios morfoclimáticos no Brasil. Universidade de São Paulo, Instituto de Geografia, 1970.

O Pantanal Mato-Grossense e a teoria dos refúgios. Revista Brasileira de Geografia, v. 50, n. 2, p. 9-57, 1988.

. Os domínios de natureza no Brasil: potencialidades paisagísticas. Ateliê Editorial, 2003.

BEZERRA, L. J. C.; MAIA, L. P. Caracterização sedimentológica dos tabuleiros pré-litorâneos do estado do Ceará. Arquivos de Ciência do Mar, v. 45, n. 1, 2012 
BIGARELLA, J. J.; ANDRADE, G. O. Considerações sobre a estratigrafia dos sedimentos cenozóicos em Pernambuco (Grupo Barreiras). Arquivos do Instituto das Ciências da Terra, v. 2, n. 2, p. 14, 1964.

BRASIL. Companhia de Pesquisa de Recursos Minerais - CPRM. Atlas Digital de Geologia e Recursos Minerais do Ceará. Mapa na escala 1:500.000. Serviço Geológico do Brasil. Ministério das Minas e Energia. Fortaleza, 2003.

CEARÁ. Assembleia Legislativa. Caderno regional da bacia do Curu / Conselho de Altos Estudos e Assuntos Estratégicos, Assembleia Legislativa do Estado do Ceará; Eudoro 103 Walter de Santana (Coordenador). - Fortaleza : INESP, 2009. 113p. : il. - (Coleção Cadernos Regionais do Pacto das Águas. v. 4).

Secretaria dos Recursos Hídricos. Plano Estadual de Recursos Hídricos (Planerh). Fortaleza: SRH, 1992.

CLAUDINO SALES, V.; LIRA, M. V. MEGAGEOMORFOLOGIA DO NOROESTE DO ESTADO DO CEARÁ. Caminhos de Geografia, v. 12, n. 38, 2011.

CUNHA, S. B.; GUERRA, A. J. T. Geomorfologia e meio ambiente. $4^{\circ} \mathrm{ed}-\mathrm{Rio}$ de Janeiro: Bertrand Brasil, 2003.

FERNANDES, A. Fitogeografia Brasileira-Fundamentos Fitogeográficos: Fitopaleontologia, Fitoecologia, Fitossociologia, Fitocorologia. $1^{\text {a }}$ Parte. Fortaleza: UFC, 2007.

FIGUEIREDO, M. A. 1997. A cobertura vegetal do Ceará (Unidades Fitoecológicas). In: Atlas do Ceará. Governo do Estado do Ceará; IPLANCE, Fortaleza. 65p.

GORAYEB, A. et al. Aspectos geoambientais, condições de uso e ocupação do solo e níveis de desmatamento da bacia hidrográfica do rio Curu, Ceará-Brasil. GEOGRAFIA (Londrina), v. 14, n. 2, p. 85-106, 2005.

HOWARD, J. A.; MITCHELL. Phyto-geomorphyc classification of the landscape. Geoforum, ll.Pergamon. London, 1980. p.85-106.

HOWARD, J. A. Remote sensing of forest resources- Theory and application. Chapman e Hall. London, 1991. 243 p.

MAIA, R. P.; BEZERRA, F. H. R.; CLAUDINO SALES, V. Geomorfologia do Nordeste: concepções clássicas e atuais acerca das superfícies de aplainamento nordestinas. Revista de Geografia (Recife), v. 27, n. 1. Esp, p. 6-19, 2010.

LANDIM NETO, F. O. et al. Diagnóstico ambiental e zoneamento funcional do estuário do rio Curú: subsídios para a gestão local e regional. Revista Geoaraguaia, v. 3, n. 1, 2013. 
PASSOS, E. Fitogeomorfologia e análise ambiental. Revista Ra'e Ga. Noo1, Curitiba-PR, p. 143158. 1997.

- Classificação fitogeomorfológica de ecossistemas florestais numa porção do setor oriental do Estado do Paraná. 256 p. Tese (Doutorado em engenharia florestal) - Universidade Federal do Paraná, Curitiba. 2000.

SOARES, F. M. Levantamento dos aspectos fisico-naturais da Bacia do Rio Curu-CE. Rev. Geol.(Brazil), v. 17, p. 52-73, 2004.

SOUZA, M. J. N. "Contribuição ao estudo das unidades morfoestruturais do Estado do Ceará". In: Revista de Geologia-UFC. Fortaleza. V. 1. p. 73-91, 1988.

SOUZA, M. J. N.; OLIVEIRA, V. P. V. Os enclaves úmidos e sub-úmidos do semi-árido do nordeste brasileiro. Revista Mercator. Fortaleza. v. 5, n. 9, 2006.

SOUZA, M. J. N.; SANTOS, J. O.; OLIVEIRA, V. P. V. Sistemas Ambientais e Capacidade de Suporte na Bacia Hidrográfica do Rio Curu-Ceará. Revista Continentes (UFRRJ), v. 1, n. 1, p. 119-143, 2012.

\section{AGRADECIMENTOS}

Agradeço ao Conselho Nacional de Desenvolvimento Científico e Tecnológico (CNPq) por fomentar a pesquisa no âmbito da iniciação científica e a Universidade Estadual do Ceará (UECE).

Recebido em: 14/08/2016

Aceito para publicação em: 01/10/2016 